\title{
IDIOMA Y CIUDADANIA LITERARIA EN HOLY SMOKE, DE GUILLERMO CABRERA INFANTE
}

\author{
POR \\ ANTONIO PRIETO TABOADA \\ Lehigh University
}

En una novela de espionaje del escritor cubano Luis Rogelio Nogueras, el narrador recoge las siguientes reflexiones del protagonista, un agente del gobierno castrista destacado en los Estados Unidos:

Cinco años sin volver a Cuba. Quizá a él también se le estaba olvidando un poco el español. No el español en conserva que se maltrata en Miami, aquel español que, en sus giros y modismos, se habra quedado detenido a medio camino entre el inglés y el caló de Pila y Colón. Sino su español. Ese que, ahora mismo, en aquel mismo instante, estarian hablando en Cuba sus viejos camaradas ...?

Las reflexiones del personaje de Nogueras en cuanto a la inevitable corrupción -o incluso la pérdida - del español a causa del exilio en un país de habla extranjera podrían explicar uno de los rasgos más notables de Holy Smoke, la última obra de Guillermo Cabrera Infante: el hecho de que haya sido redactada directamente en inglés. Al mismo tiempo, las palabras anteriores ilustran las profundas repercusiones del cruce de la frontera lingüística que Cabrera Infante efectúa en esta obra: la distinción entre el español vivo de la Cuba revolucionaria y el español "en conserva" de los cubanos exiliados transforma el idioma en bandera nacional y pone de manifiesto los conflictos, no ya culturales sino políticos, que contribuyen a fijar los límites de un idioma y de una literatura nacional ${ }^{2}$. En esos conflictos participa - quiéralo o no- todo intento de situar más acá o más allá del campo de la literatura cubana el conjunto de obras producidas fuera de Cuba. A base de ellos, y siguiendo el ejemplo del personaje de Nogueras, sería fácil - demasiado fácil- politizar la adopción del inglés por parte de Cabrera Infante en Holy Smoke y la consiguiente crisis de una literatura "cubana" del exilio que este libro sugiere. Ello supondría, sin embargo, negarnos a volver la vista hacia la otra dirección en la

${ }^{1}$ Luis Rogelio Nogueras, Y si muero mañana (1978); (La Habana: Editorial Letras Cubanas, 1980) 35.

${ }^{2}$ Para un estudio ejemplar de la forma en que se libran esos conflictos en el seno de la lengua francesa véase Renée Balibar y Dominique Laporte, Burguesía y lengua nacional, trad. de Lluis María Todó (Barcelona: Editorial Avance, 1976). 
que apunta Holy Smoke, vale decir, hacia las dificultades de recepción y de ubicación de una obra creada en el contexto de una lengua y una literatura ajenas.

A pesar de estar escrito en otro idioma, el último libro de Cabrera Infante reitera ciertas constantes de sus obras anteriores y se rige por la misma estética que éstas formulan en conjunto. Al igual que las crónicas de cine recogidas en Un oficio del siglo XX y que los ensayos de $O$, Holy Smoke se aparta del terreno de la ficción para ofrecernos la historia del descubrimiento, el cultivo, los usos y los abusos del tabaco. Al igual que Tres tristes tigres, por otro lado, la vertiente informativa y referencial del texto se encuentra continuamente desplazada por el juego verbal. Para el lector ávido de información, en Holy Smoke se prodigan las curiosidades: desde las chimeneas humanas que, puro en boca, se les figuraban los taínos a Colón y sus acólitos hasta la reciente subasta neoyorquina de veinticinco habanos por más de dos mil dólares; desde el pintoresco oficio del lector de tabaquería y las absurdas pretensiones del notorio Davidoff, el tabaquero que bautiza sus productos con el nombre de vinos franceses, hasta la extensa discusión de lo que significa la vitola o lo que se debe hacer con el anillo del tabaco. Pero según se infiere de lo anterior, precisamente la enciclopédica disparidad de los datos que se nos brindan en la obra la convierte ya en una parodia del género informativo en el que parecería inscribirse.

Por si esto fuera poco, mientras Tres tristes tigres se consituía como "una galería de voces ${ }^{m}$ que entonaban en diversos registros una misma historia, Holy Smoke se arma como un mosaico de textos que reúne, en torno al tema central del tabaco, los más heteróclitos fragmentos del libro de la cultura. Junto a las previsibles citas de los clásicos del tema hallamos textos de Mallarmé y del New York Times, anuncios de cigarrillos y pasajes de las crónicas de Indias, así como incontables escenas de películas protagonizadas por el tabaco en sus distintos avatares. Este juego intertextual —además de despejar nuevamente los humos de la al ta literatura mediante un improbable compendio de "la cultura total[:] De Moebius y el continuo espacio-tiempo a King Features, Syndicate", como se decía en Tres tristes tigres ${ }^{4}$ - hace del arte de la cita una cita del arte al poner en evidencia el carácter del libro como artefacto cultural. No en vano la figura de Marcel Duchamp se nos presenta en estas páginas como una de sus musas:

${ }^{3}$ Así es como el propio Cabrera describía la obra en una enirevista con Rodríguez Mor:egal. Véase Emir Rodríguez Monegal, "Las fuentes de la narración”, Mundo Nuevo, 25 (1968): 46.

${ }^{4}$ G. Cabrera Infante, Tres tristes tigres, (1967); (Barcelona: Scix Barral, 1970) 356.

${ }^{5}$ Según Cabrera, el editor norteamericano de sus obras fue quien le sugirió escribir el libro: "You ought to write a book about cigars, you know", le dice éste al futuro autor, que está entretenido fu mándose un tabaco en Holy Smoke (New York: Harper and Row, 1985) 164. Sin embargo, la inspiración estética de la obra proviene de una fotografía de Duchamp montando bicicleta: "In the photo, a jewel by Carticr [Bresson], the worn-out bicycle has only one wheel left and it is almost a circle and radials: a study in geometry. But Duchamp holds his cigar aloft, just like the Statue of Liberty ...", 163-164. Después de la conversación con el editor, Cabrera sigue fumando y recuerda la foto: "I remem- 
en Holy Smoke el nivel primario de referencia no corresponde a una realidad extratextual, sino a los objets trouvés que proporcionan los textos ajenos. De ahí que la vertiente informativa de Holy Smoke acabe convirtiéndose - a imagen de su combustible referente- en humo, en nada. A ello contribuye también, por último, el hecho de que los textos ajenos valgan de pre-textos para un obsesivo juego verbal que se cifra por igual en los juegos de palabras, en las numerosas frases hechas que se deshacen con inesperados giros ("as a matter of fiction", "the devil's avocado") y en la impenitente aliteración que se anuncia ya en la referencia inicial a un "vicious but vivacious villain ... in a cavernous crypt". En la medida en que las semejanzas fonéticas y ortográficas son las que a menudo determinan la selección del significante, en esta obra se privilegia una vez más el orden propio del lenguaje y se recalca al mismo tiempo la función de ese orden como mecanismo generador del significado. "Rhyme has its reason", explica el autor (p. 138). Como en Tres tristes tigres, nos encontramos en pleno carnaval de la palabra?.

Aun así, las diferencias entre Holy Smoke y las obras anteriores de Cabrera Infante no son menores que sus semejanzas. Entre ellas cabe destacar que, mientras en Tres tristes tigres y en La Habana para un Infante difunto se intentaba recuperar un ámbito cubano (o al menos habanero) alejado por el tiempo y la distancia, en Holy Smoke ese ámbito se identifica casi por completo con la imagen sinecdóquica del habano y se pierde en el juego intertextual en torno a ella. Si bien esta renuncia al proyecto de recuperación se podría vincular con el reconocimiento, ya expresado en aquellas dos obras, de que tanto la escritura como la memoria no son más que traductoras traidoras, es preciso vincularla igualmente con una toma de conciencia del momento y del lugar de la escritura que significa la entrada literaria de Cabrera Infante a la actualidad del exilios. Más allá de la ruptura con el discurso del pasado y con la modalidad nostálgica, tan frecuentes en las obras del éxodo cubano, esa entrada se efectúa ante todo por la puerta del idior.a. Al adoptar el inglés en Holy Smoke, Cabrera Infante reconoce su lugar - lingüístico, literario, cultural- de enunciación e induce a la literatura y a la crítica del exilio cubano a hacer lo mismo.

Aunque es cierto que Cabrera entra en contacto con el inglés ya en la época de su formación intelectual en el marco de la literatura angloamericana y de una industria cinematográfica en la que sobresalen las producciones de Hollywood,

bered Duchamp and made some more rings [with the smoke]. Things are in smoke, art is in the rings. The wheel of a bicycle can be a ring too. The book, I thought, could be for Duchamp ...", 164 .

${ }^{6}$ Holy Smoke, 1. Los números de páginas entre paréntesis en el texto se refieren a esta obra.

7 Véase Antonio Prieto, "Tres tristes tigres: El carnaval de la palabra", Tesina de Licenciatura. (Princeton University, 1976).

- Cabría recordar, sin embargo, que esa entrada ya se emprende en ciertas crónicas de $O$ (Barcelona: Seix Barral, 1975). Véase en especial "Eppur si muove? (De Londres considerado como una torre de Babel de Pisa hecha de Jell'o)" y "Desde el Swinging London". 
es sólo a consecuencia de haberse radicado en un país de habla inglesa que su adopción literaria de ese idioma cobra sentido y, al cabo de veinte años de vivir dentro de una cultura dominante cuya lengua no es el español, se perfila en un final como una necesidad. Holy Smoke, por ende, anticipa hasta cierto punto la futura trayectoria de la literatura escrita fuera de Cuba en circunstancias análogas 9 . Pero a pesar de esas circunstancias y a despecho del personaje de Nogueras, el significado del gesto de Cabrera Infante al adoptar el inglés no se agota ni en el desgaste ni en la pérdida de su idioma natal, según ya lo indican el reconocimiento de que goza Cabrera dentro de las letras hispanoamericanas y la correspondiente difusión de su narrativa en el mundo de habla española. Entre los posibles motivos de ese gesto cabría incluir también la aparente desconfianza del autor en las traducciones de sus obras anteriores al inglés ${ }^{10} y$ las ventajas de esta lengua - en contraste con el mero español-para el juego verbal, sin pasar por alto ni cierto cosmopolitismo neovanguardista ni una indudable voluntad polémica. Al renunciar, hace unos años, al "club" del boom narrativo latinoamericano, Cabrera cuestionaba el concepto mismo de "To latinoamericano" $\mathrm{y}$, después de describirse como "el único escritor inglés que escribe en español", concluía: "No quiero clubes ni sociedades secretas .... Es por" eso que ..., cuando me hablan del boom y me asocian con esa masonería mínima, siempre respondo: 'Include me out' ..." . Mediante la publicación deHoly Smoke Cabrera parecería cuestionar también el concepto de una literatura "cubana" del exilio y a la vez excluirse de ella al pasar al dominio de otroidioma y de otra literatura.

La pregunta clave que formula tácitamente este libro - la de si puede haber una literatura cubana escrita en un idioma que no sea el español-lleva a sus últimas consecuencias la cuestión de la cubanidad de las obras creadas en el exilio y nos obliga a pensar dicha cubanidad como un interrogante. La importancia de ese interrogante tal vez no radique tanto en las respuestas inmediatas que le podamos dar como en la indagación de sus implicaciones, entre las que habría que contar ante todo la definición de qué es una literatura nacional y de cuál es su relación con el idioma, así como el carácter histórico e

\footnotetext{
${ }^{9}$ No obstante, el movimiento del español hacia el inglés pasando por el Spanglish no es la única alternativa de esa trayectoria. Piénsese, por ejemplo, en un escritor como Rolando Hinojosa-Smith, nacido y criado en los Estados Unidos, que escribe tanto en inglés como en español y a quien se le otorga el premio Casa de las Américas en 1976 por su novela Klail Cily y sus alrededores (La Habana: Casa de las Américas, 1976).

${ }^{10}$ Así lo sugiere la insistencia de Cabrera de colaborar en ellas. Véase G. Cabrera Infante, Three Trapped Tigers, trad. de Donald Gardner y Suzanne Jill Levine con la colaboración del autor (New York: Harper and Row, 1971) y G. Cabrera Infante, Infante's Inferno, trad. de Suzanne Jill Levine con la colaboración del autor (New York: Harper and Row, 1984).

11 G. Cabrera Infante, "Include me out", en Requiem for the "Boom" -Premature?: A Symposium, compilación de Rose S. Minc y Marilyn R. Frankenthaler (Montclair, NJ: Montclair State College) 12, 18.
} 
incluso revisionista de esa definición misma, la cual se renueva continuamente a partir de los debates estéticos e ideológicos que se entablan dentro de toda institución literaria nacional. Según ya indicáramos, el cuestionamiento de la cubanidad de la literatura del exilio también nos obliga a tener en cuenta, por otro lado, la incómoda ubicación de esa literatura en su nuevo contexto. Al ir más allá del español, Holy Smoke no sólo demuestra, en términos lingüísticos, la ausencia, por motivos políticos, de una comunidad de recepción entre la literatura revolucionaria cubana y la literatura escrita fuera de Cuba sino que pone de relieve la dificultad de mantener una comunidad semejante en el interior de la literatura del exilio misma. Esa dificultad tal vez se perciba con mayor intensidad en los obstáculos que la obra de Cabrera plantea para la crítica. Ya que el juego verbal que viene a ser su verdadero protagonista se efectúa en otro idioma, Holy Smoke marca los límites de nuestra competencia como criticos cuya lengua materna no es el inglés y cuya tarea docente, por lo demás, nos asigna el papel de representantes de la lengua y la tradición hispánicas en una cultura extranjera.

$\mathrm{Al}$ acudir a la crítica lingüísticamente capacitada para apreciar la obra, comprobamos de nuevo su incómoda ubicación, esta vez en lo tocante al dominio de la literatura angloamericana. Ello se evidencia no tanto en las discrepancias en cuanto al valor de Holy Smoke que expresan las distintas reseñas de la obra publicadas en la prensa británica y norteamericana, sino más bien en lo que esas reseñas - desde la del Observer londinense hasta la del New York Review of Books - tienen en común ${ }^{12}$. Aparte de los aciertos y los desaciertos apuntados en ellas, aparte de las comparaciones elogiosas con otros maestros del inglés adoptado (como Conrad y Nabokov) y de los reparos en cuanto a las torpezas en el uso de la lengua, todas las reseñas practican una idéntica descontextualización de la obra. El nuevo estado civil de Cabrera Infante como súbdito británico parece valerles de justificación a sus autores para pasar por alto el significado de Holy $S$ moke con respecto a la literatura del exilio cubano y para efectuar, de esta forma, un "borrón" de la misma comparable al que Octavio Armand le ha reprochado a la crítica hispanoamericana ${ }^{13}$. Además de la equiparación superficial entre ciudadanía civil y ciudadanía literaria, la

\footnotetext{
${ }^{12}$ Las reseñas firmadas que he podido consultar son las siguientes: Anthony Burgess, "Tobacco Road", The Observer [Londres], (13 de octubre de 1985): 27; John Butt, "Punning and Puffing", Times Lilerary Supplement, (29 de agosto de 1986): 946; Malcolm Deas, "Read, Rattle and Roll", London Review of Books, (6 de febrero de 1986): 10; Enrique Fernández, "Havana Vice: A Cautionary Tale", The Village Voice, (25 de marzo de 1986): 43-44; John Gross, "Holy Smoke, by G. Cabrera Infante", The New York Times, (7 de febrero de 1986): 22; Josh Rubins, "Puffs", The New York Review of Books, (8 de mayo de 1986): 35; Jorge Saralegui, "Infante on Fire", San Francisco Review of Books, 11 (Summer 1986): 16, 23; Anthony Schmitz, "Holy Smoke, by G. Cabrera Infante", The New York Times Book Review (2 de marzo de 1986): 25.

${ }^{13}$ Octavio Armand, "Minicurso para borrar al escritor cubano del exilio", Escandalar, Łomo 3, número 2 (1980): 86-89.
} 
lectura descontextualizada de Holy Smoke revela otra confusión más profunda todavía - una confusión entre el idioma en que está escrita la obra y la tradición literaria dominante de ese idioma-y lleva a cabo, a nombre de este último, una apropiación del libro que constituye la otra cara de las exclusiones que también se decretan a nombre suyo (valga de ejemplo una vez más la cita de Nogueras). El anglocentrismo - por así decirlo - de dicha lectura se manifiesta asimismo en la premisa, compartida por la mayoria de las reseñas, de que Cabrera Infante adopta el idioma ajeno exclusivamente con el fin de naturalizarse en la república de las letras angloamericanas. Sólo asi se explica que no se tenga en cuenta ni el significado polémico de esa adopción dentro de la tradición literaria del autor ni las ventajas que el inglés le brinda a éste desde el punto de vista de su propia estêtica, las cuales Cabrera aprovecha con tal despreocupado virtuosismo que podríamos sospechar que el idioma otro representa otro texto ajeno para él, es decir, un pre-texto más de la escritura ${ }^{14}$.

Enrique Fernández, el crítico bilingüe del Village Voice, es el únicoque nota el aprovechamiento estético del inglés en Holy Smoke y que reconoce, ademås, la rica textura idiomática del libro: "Cabrera Infante is like [a] deprived child in a linguistic candy shop", escribe. "Under the surface", continúa Fernández, "Holy Smoke is a bilingual book. The incompatibilities of the two languages [English and Spanish] give the text its peculiar flavor and humor .... But most of it won't tickle you right away - unless you're already as bilingual as the text. It's an acquired taste ${ }^{n 15}$. Se puede decir que Cabrera Infante, por lo tanto, no es tan sólo un escritor inglés que escribe en español sino que, en Holy Smoke, demuestra ser también un escritor de habla al fin y al cabo española que escribe en inglés, lo cual garantiza, en definitiva, la resistencia de la obra a dejarse encuadrar en un solo dominio crítico o en una sola comunidad de recepción (su lector ideal, como bien observa Fernández y según lo confirma su capacidad misma de observarlo, es el lector bilingüe). De ahí la posición doblemente marginal de esta obra frente a las literaturas cubana y angloamericana, o sea, frente a las dos literaturas dominantes dentro de las que opera sin ubicarse del todo en ninguna de ellas. Esa misma desubicación, sin embargo, podría entenderse - si bien, en última instancia, erróneamente - como una entrada a otro lugar: no ya al exilio, sino al espacio literario igualmente descentrado que

\footnotetext{
${ }^{14}$ En su reseña de la obra John Butt [sic] sí comenta la irreverente actitud de Cabrera hacia el inglés, pero no sus implicaciones: "Cabrera Infante has done more than follow the same difficult path as Conrad and Koestler. They both played by the rules of the club which had lately admitted them, but Cabrera has decided to do to the language of Shakespeare what he previously did to that of Cervantes: improve it. This, to put it mildly, is a daring liberty ..." ("Punning and Puffing", 946). Cabrera nuevamente se disocia de todo tipo de "masonería mínima".

${ }^{15}$ Fernández, "Havana Vice", 44.
} 
ocupa la literatura de las minorías étnicas hispanas de los Estados Unidos, es decir, la literatura chicana y neorriqueña ${ }^{16}$.

Además de su ubicación marginal y de los correspondientes problemas de recepción, entre Holy Smoke y esa literatura se establecen varios puntos de contacto a partir de un trabajo semejante sobre el idioma. Así, por ejemplo, el bilingüismo que tan a menudo encontramos en la literatura chicanorriqueña y que Fernández también constata en Holy Smoke al declarar que en esta obra "[Cabrera Infante] writes in an English that is also a subtle variant of Spanglish ..."17. Cabría añadir asimismo la subversión del inglés que se advierte en algunos textos neorriqueños, en los que se explotan, como en Holy Smoke, las frases hechas y el sistema fonológico de la lengua ${ }^{18}$. Al igual que esos textos, la úl tima obra de Cabrera Infante podria formar parte de esa "literatura menor" que Deleuze y Guattari definen como "la literatura que una minoría hace dentro de una lengua mayor" mediante "un ejercicio menor" de dicha lengua ${ }^{19}$. Es evidente, no obstante, que Holy Smoke no se puede incluir tampoco en la misma categoría que la literatura de las minorias hispanas. Valga recordar que la subversión lingüística que Cabrera Infante practica en esta obra ya caracterizaba sus textos en español. En el caso suyo, por consiguiente, la subversión del idioma ajeno no responde a la misma coyuntura de injusticia y de marginación social que en el de los escritores chicanos y neorriqueños, ni está cargada debido a ello- de las mismas implicaciones ideológicas y políticas, las cuales, por lo demás, se articulan explícitamente en la temática denunciatoria que esos

\footnotetext{
${ }^{16}$ Según Efraín Barradas, mientras en los Estados Unidos la poesía neorriqueña se considera "como curiosidad etnológica", en Puerto Rico o bien se ignora o se le "niega su puertorriqueñidad", Efraín Barradas, "Introducción", Herejes y milificadores: Muesirce de poesta puertorriqueña en los Estados Unidos, comp. de Efraín Barradas y Rafael Rodriguez (Río Piedras: Ediciones Huracán, 1980) 11. En cuanto a la literatura chicana, su desubicación se refleja en las opiniones de sus propios creadores. Mientras algunos la consideran como parte de la literatura norteamericana, otros afirman la imposibilidad de limitarla a un sólo dominio literario. "No creo que sca correcto clasificar a la literalura chicana como literatura española ni inglesa ni norteamericana", dice el poeta Alurista, en Bruce-Novoa, La literatura chicana a través de sus autores, trad. de Stella Mastrangelo (México: Siglo Veintiuno, 1983) 274. Esta diversidad de opiniones demuestra, por lo demás, que ni la literatura chicana ni la neorriqueña son entidades homogéneas, sino que dentro de ellas hay una gran variedad de posiciones, así como distintos grados de acercamiento a las literaturas mayores que les sirven de marco.

17 Fernández, "Havana Vice", 44.

18 Véase particularmente Puerto Rican Obiluary (New York: Monthly Review Press, 1973), de Pedro Pietri, en donde los clichés sacados de contexto y el juego de la rima a veces demasiado fácil, a veces deliberadamente forzada- hacen resaltar el absurdo de la sociedad en que vive el poeta. El juego fonético con el inglés también se nota en algunos poemas de Víctor Hernández Cruz (véase "Financial Report" y "Art-this", en Barradas y Rodríguez, Herejes, 132-136.

${ }_{19}$ Gilles Deleuze y Felix Guattari, Kafka: Por una literatura menor, trad. de Jorge Aguilar Mora (México: Biblioteca Era, 1983), 28 y 32.
} 
escritores manejan en sus obras. Pero aun cuando el último libro de Cabrera Infante no quepa en una literatura menor bajo el mismo título que dichas obras, lo que importa destacar, en un final, es la posibilidad de compararlo con ellas en la medida en que esa posibilidadilustra una vez más la complejidad del contexto literario en el que se produce y en el que entra a participar - aun sin proponérselo-la literatura del exilio cubano. Es en este sentido, aún más que en lo tocante a la pérdida del español, que Holy Smoke anticipa la trayectoria de los escritores cubanos más jóvenes residentes en los Estados Unidos, algunos de los cuales ya han empezado a tomar conciencia de su contexto literario y de su relación -no siempre fácil-con la literatura de las minorias hispanas de este país ${ }^{20}$ a medida que el exilio se vuelve condición de vida permanente para ellos. Aunque Cabrera Infante tampoco cabe dentro de este grupo de escritores por el hecho de pertenecer a una generación anterior cuya iniciación literaria fuera muy distinta, la ruptura temática y lingüística con esa generación que marca su última obra lo acerca al contexto y a la problemática de los escritores más jóvenes $\mathrm{y}$, lo que es aún más importante, logra que esa problemática reclame la atención más amplia que se le concede solamente a la obra de un escritor consagrado. Es cierto que Holy Smoke es "minor Cabrera Infante", según reza una de las reseñas de la obra ${ }^{21}$, pero lo es por motivos que el reseñista no sospecha. A pesar de todo - tal vez hasta del propio autor-Holy Smoke comparte uno de los rasgos fundamentales de una literatura menor: el de asumir la representación de una colectividad ${ }^{22}$.

${ }^{20}$ Vease Eliana S. Rivero, "Hispanic Literature in the United States: Self-Image and Conflict”, Revista Chicano-Riqueña, tomo 13, números 3-4 (1985), 173-192.

21 Rubins, "Puffs', 35.

${ }^{22}$ Véase Deleuze y Guattari, Kafka, 30. 